\title{
Guidelines for Facilitating User-Centric Product and Service Development in an Open Innovation Environment
}

\author{
Lotta Haukipuro \\ University of Oulu, GenZ project \\ Oulu, Finland \\ lotta.haukipuro@oulu.fi
}

\author{
Leena Arhippainen \\ University of Oulu, INTERACT Research Unit \\ Oulu, Finland \\ leena.arhippainen@oulu.fi
}

\begin{abstract}
This paper proposes guidelines for facilitating user-centric product and service development in an open innovation environment. Well-working open innovation processes and practices are key factors for involving different stakeholders into innovation and evaluation of new product and services. The purpose of these guidelines is to help create and improve open innovation environments and practices to increase the usefulness of innovation environments, and to take user experience aspects more broadly into account. The guidelines are developed based on the empirical experiences and lessons learned from case studies conducted in an open innovation environment during several years. The guidelines support adoption of open innovation environment practices in a variety of product and service development activities.
\end{abstract}

\section{INTRODUCTION}

The importance of users in generating commercially viable innovations has been recognized for decades, as, e.g., von Hippel introduced the concept of user innovation and lead user in the 80s [1],[2]. As the open innovation (OI) approach [3] emerged in new service development, elaborate networks in which companies co-create to generate new products and services have been increasingly researched and established. [4],[5]. The main shared thought in user innovation and open innovation research is the need for external knowledge for innovation [6]. According to Wilkinson and De Angeli [7] among others, the inclusion of users throughout the design process is crucial to the improved adoption of finalized solutions. They point out that the investigation of user needs has been prosperous, especially for the development of new products. The significance of open innovation and end-user involvement has been recognized also at the European Union level where the living labs strategy was established in the 2000s by the European Commission and furthered with the Open Innovation Strategy and Policy Group that promotes open and collaborative innovation processes [8],[9].

The open innovation is a broad concept of which several definitions exist as scholars and practitioners hold their own type of definitions [6],[10]. For the past decade, the concept has increasingly gained popularity within academic research, practitioners and policymakers. [11],[12] The concept of open innovation, originally introduced by Henry Chesbrough [3], encouraged companies to acquire outside sources of innovation to improve products or services and to shorten the time required to bring products into the market, and to market or internally release the developed innovation that does not fit the company's business model but could effectively be used elsewhere.

Living lab approach has become popular in involving users into innovation and evaluation process of products and services and has been under the investigation since the 2000s. However, there is a need for further studies on the living lab processes and methods [13],[14]. Living labs operate as intermediaries among citizens, research organizations, companies, cities and regions for joint value co-creation, rapid prototyping or validation to scale up innovation and business. Living labs are driven by two main ideas: involving users as co-creators on equal footing with the other participants and experiments in real-world settings [15]. As the multi-method approach is characteristic to living labs, a broad variety of user involvement methods have been utilized in living lab activities. Tang and Hämäläinen [16] describe the living lab as a concept and methodology, which combines different types of research methods including traditional and ICT-enabled methods.

Unlike a single field trial or a user test (e.g. usability test), open innovation environment (e.g. living lab) approach involves users in all stages of research and development and the product development lifecycle. The approach is relevant especially when studying comprehensively user experiences before, during and after the use of products or services [17]. User experience (UX) is a significant factor for the success of products, and thus just good usability is not enough anymore [18],[19]. This is one reason why UX has become a central target in product and service design [20]. Over the last two decades, the term user experience has spread everywhere in research and industry. A wide interest on UX over two last decades has changed the term from a buzzword to a considerable key asset of business and development. General public seems to user the term UX as a synonym for user interface and usability. However, user experience is not the same issue than user interface or usability. Instead, user experience has a larger meaning and both user interface and usability of the product or services have influences on subjects' user experiences. ISO 9241-110:2010 standard defines user experience as: "a person's perceptions and responses that results from the use and/or anticipated use of a product, system or service" [21]. Especially studying 
anticipated user experiences (AUX) in the early phase of the development process can provide valuable inputs and insights for the design of new product and services [22]. Even though the interest in user experience in industry and academy has been high for a long time, there been recognized lacks of finding systematic methods for UX research and take UX issues into account in different phases of the design and development [17],[22]. In an open innovation environment, one challenge is to find the most suitable methods for different phases of the open innovation process (e.g. user involvement, co-creation and UX evaluation). It is important to choose the right methods to support several ways of user participation and collection of experiences, ideas, values and opinions. This will have influences also on how to motivate users [23] to participate in open innovation environments (OIE). Therefore, it is important that processes and practices in OIE can support efficient user involvement.

In this paper, we propose guidelines for facilitating usercentric product and service development in an open innovation environment. The aim of these guidelines is to facilitate creating and improving open innovation environments (e.g. living lab) and practices in order to enhance the value of innovation environments. Moreover, the aim is to support for taking user experience aspects broadly into account to build a diverse user database, motivate online and on-site user participation and provide valuable experiences and results for innovation environment stakeholders including end-users. Therefore, these guidelines were evaluated by utilizing user experience heuristics.

\section{RELATED WORK}

In this chapter we present related work regarding open innovation, living labs and user experience. In a user-centric product and service development in open innovation environments it is necessary to have knowledge of the user experience research and human-computer interaction research. The guidelines presented in this paper are inspired by the general heuristics and design approaches that have been developed and utilized in the field of human-computer interaction (HCI) during the last three decades [24],[25].

\section{A. Open innovation approach}

The importance of users in generating commercially viable innovations has been recognized for decades. Von Hippel introduced the concept of user innovation already in the $80 \mathrm{~s}$ [1],[2]. After the open innovation approach [3] was introduced in new service development, elaborate networks in which companies co-create new products and services have been increasingly researched and established. [4],[5]. The main shared thought in user innovation and open innovation research is the need for external knowledge for innovation [6]. According to Wilkinson and De Angeli [7] among others, the inclusion of users throughout the design process is crucial to the improved adoption of finalized solutions. They point out that the investigation of user needs has been prosperous, especially for the development of new products.

Living labs are an example of organizations or intermediates that deploy the open innovation approach. To increase the understanding of the benefits of the living labs it is important to explore the real-life living lab activities conducted in the innovation environment. According to Bergvall-Kåreborn and Ståhlbröst [26], a living lab can support innovation processes by enabling users to elaborate and evaluate the value of the service in their context. From the research perspective, the shift towards a more user-centric development of products and services has created a fruitful and unique research environment in which new methods have been developed and piloted in diverse environments; public and private sector developers, as well as research institutes, have been involved and for the first time in this scale, end-users have become equal co-developers.

\section{B. User experience approach}

The products and services should provide good user experiences in order to success, and thus UX approach has become a central target in product and service design and evaluation and new methods have been developed for UX research during the last two decades [18],[19],[17]. Despite this wide interest in UX in industry and academy, there has been recognized needs for creating systematic methods for user experience research [17]. In many expert evaluations, Ten Usability Heuristics [25] are still the most used criteria, even though the approach in them is quite narrow focusing only on usability aspects. However, when taking user experiences into account the approach needs to be wider. Especially in open innovation environments it is needed to ensure that new services and products can form positive experiences for users.

Alben [27] introduced the first general UX criteria for effective interaction design. Väänänen-Vainio-Mattila and Wäljas [20] have presented service UX evaluation heuristics. Korhonen and Koivisto have created playability heuristics for mobile games [28]. Colombo and Pasch [29] have presented ten heuristics for an optimal user experience from flow theory perspectives and then applied them to the HCI area. A flow experience [30] is an optimal experience, where a user is totally focused on person's own task and forgot all surroundings. However, it is important to notice that an optimal experience is a specific type of experience and all user experiences are not optimal.

The definition of user experience which refers to "person's perceptions and responses resulting from the use and/or anticipated use of a product, system or service" [21] shows that user experience means a more comprehensive approach than only optimal experiences. All these heuristics are important, but they focus on certain specific focus area or the approach is too narrow when there is a need comprehensively to take user experience into account in user-centric product and service development. Therefore, general guidelines for user experience research have been created for design and evaluation [31] Heuristics and guidelines that professionals can utilize during the different phases of the developed are regarded as relatively low-cost methods because they can be utilized especially in the early development phases. These general user experience heuristics have been developed for any kind of product or service design and evaluation context [31].

In this paper we discuss whether these user experience heuristics can be applied in an open innovation environment context and how they should be modified. 
Open innovation environments (e.g. living labs) should be a natural and continuous practice in product and service development [32], and therefore we decided to create guidelines for facilitating user-centric product and service development in an open innovation environment. The creation of these guidelines is inspired from the HCI field, but the data and experience of open innovation environments are gathered from the broad qualitative studies.

\section{METHODOLOGY}

In qualitative research, the benefits of the case study approach have been recognized in different fields [33],[34],[35],[36],[37],[38],[39],[40]. Yin [34],[35] defines the case study as "an empirical inquiry that investigates a contemporary phenomenon within its real-life context when the boundaries between phenomenon and context are not clearly evident and in which multiple sources of evidence are used". The fundamental thought beyond case research is the multifaceted view it can provide of a situation in its context [38]. The relation between a phenomenon and its context can be understood through the case study approach [37]. Compared to the quantitative research approach, depth and comprehensiveness [41] are the defining characteristics of qualitative case research. Hence, the case study enables deep understanding of a specific phenomenon and is particularly suitable for exploration of a new or unique phenomenon, for example [33]. Case study method has been criticized of lacking rigor methodology and objectivity. Johnston et al. [42] take a stance on the criticism presented towards case research by pointing out that case research is an applicable and reliable research method in business studies when the research is wellplanned and theory-based, and the research design logical and systematic. Furthermore, the findings must be independently evaluated and confirmed by multiple evaluators. Essential considerations when designing case research are the definition of the unit of analysis, the selection of appropriate cases and, the decision on data collection [42].

The data collection methods utilized in this research consist of semi-structured in-depth interviews, discussions, meetings, meeting memos, workshop data, different documentation of activities, reports and data collected through a digital user involvement tool. Interviews [43] were used as the primary data collection method, consisting of altogether 70 semi-structured in-depth interview sessions [32]. In several sessions, there were multiple interviewees. The interviews were recorded, transcribed, and notes were taken. The informants were selected so that they were identified to possess a significant role in innovation activities and able to reveal important information regarding the product and service development activities conducted in the open innovation environment.

In the analysis of the data, triangulation [44],[45], thematic analysis, for instance [46], and categorization techniques were applied. Triangulation is a process in which multiple data collection and analysis methods are used to search for convergence [45]. Data collection and data analysis was also conducted concurrently as it helps identify gaps in the collected data [47],[48].

\section{AN EVALUATION OF THE INITIAL SET OF GUIDELINES}

Based on the long-term studies in open innovation environments (e.g. living lab activities, user involvement, cocreation), we created guidelines for facilitating user-centric product and service development in an open innovation environment. The aim of these guidelines is to help create new and improve existing processes and practices to facilitate usercentric product and service development in the open innovation environment. The guidelines are described below:

- Functioning open innovation process

- Facilitation

- Resource-driven operations

- Funding model

- A versatile set of methods

- Digital tools

- Access to users

- Operating model for user management, involvement and motivation

- A broad network of actors

- Operating model for network collaboration

- Communication and communication of results

- Follow-up.

After creating the guidelines, we evaluated them by utilizing user experience research approach. Because one aim of the OIE is to support UX aspects to take broadly into account to build a diverse user database, motivate online and on-site user participation and provide valuable experiences for stakeholders including end-users, we decided to analyze UX heuristics in an OIE context. Ten UX heuristics [31] have been created for service and product designers and developers to take UX issues into account when making design solutions or for the evaluation of products and services. In this chapter we analyze and discuss whether these heuristics are applicable in the open innovation environment as such or are modifications needed. In addition, it will be discussed if open innovation environments require an own set of heuristics or guidelines. The Fig. 1 shows the applicability of UX heuristics compared to OIE guidelines.

\section{UX Heuristics}

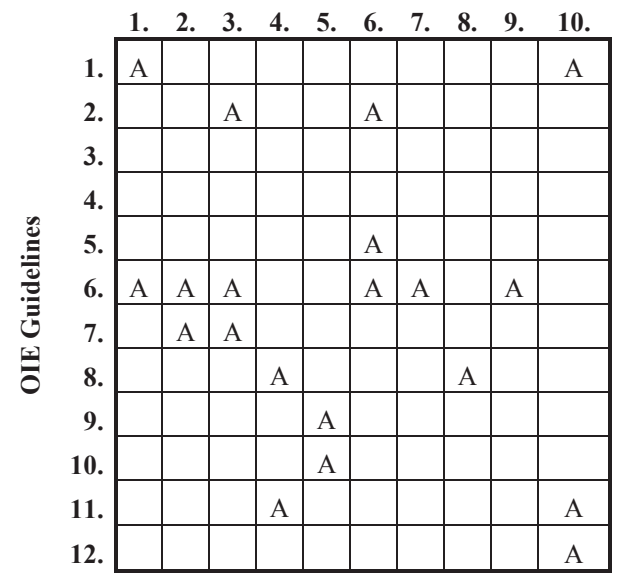

Fig. 1. Applicability of UX heuristics compared to each guideline 
TABLE I. ANALYSIS OF APPLICABILITY OF UX HEURISTIC FOR OIES. APPLICABLE $(A=$ YES, $\mathrm{N}=\mathrm{NO})$

\begin{tabular}{|c|c|c|}
\hline UX heuristics & $\mathbf{A} / \mathbf{N}$ & Comments \\
\hline $\begin{array}{l}\text { 1. Ensure } \\
\text { usability }\end{array}$ & A & $\begin{array}{l}\text { The usability of the OIE process, service and } \\
\text { tools should be ensured. The process should be } \\
\text { functioning and smooth for all stakeholders. }\end{array}$ \\
\hline $\begin{array}{l}\text { 2. Provide } \\
\text { utility } \\
\text { matching } \\
\text { with the } \\
\text { user's } \\
\text { values }\end{array}$ & A & $\begin{array}{l}\text { This is an important aspect to take into account } \\
\text { in OIE as it has an influence on user } \\
\text { participation and motivation. From a user point } \\
\text { of view, this can relate to topics: possibilities to } \\
\text { influence on development of products and } \\
\text { services, civic engagement, sustainability, etc. }\end{array}$ \\
\hline $\begin{array}{l}\text { 3. Surpass the } \\
\text { user's } \\
\text { expectations }\end{array}$ & A & $\begin{array}{l}\text { In order to succeed, OIE should surpass the } \\
\text { users' expectations. Users must have a clear } \\
\text { understanding of the purpose and activities of } \\
\text { OIE. Negative experiences can easily cause } \\
\text { negative expectations. Enabling easy and smooth } \\
\text { user involvement process (for companies) and } \\
\text { diverse participating options (for users) and tools } \\
\text { is important. }\end{array}$ \\
\hline $\begin{array}{l}\text { 4. Respect the } \\
\text { user }\end{array}$ & A & $\begin{array}{l}\text { This is a basic requirement for the OIE, which } \\
\text { utilizes user involvement. User management, } \\
\text { guidance and communication should be adequate } \\
\text { and respective throughout the process }\end{array}$ \\
\hline $\begin{array}{l}\text { 5. Design the } \\
\text { product or } \\
\text { service to fit } \\
\text { the intended } \\
\text { contexts }\end{array}$ & A & $\begin{array}{l}\text { This is important to take into account when } \\
\text { developing a new OIE, but also when updating } \\
\text { the existing one. Innovation in real-life context } \\
\text { can be enabled through a broad network of } \\
\text { actors. }\end{array}$ \\
\hline $\begin{array}{l}\text { 6. Provide } \\
\text { several } \\
\text { ways to } \\
\text { interact, } \\
\text { leave choice } \\
\text { for the user. }\end{array}$ & A & $\begin{array}{l}\text { Because OIE can have various different users, } \\
\text { user involvement practices should be designed as } \\
\text { easy, versatile and flexible. Diverse tools and } \\
\text { ways to participate should be provided for all } \\
\text { stakeholders. }\end{array}$ \\
\hline $\begin{array}{l}\text { 7. Respect the } \\
\text { user's } \\
\text { privacy and } \\
\text { security. }\end{array}$ & A & $\begin{array}{l}\text { OIE process and actors must follow GDPR. } \\
\text { Digital tools must be designed to be secure, } \\
\text { trustworthy and respect the privacy of users (e.g } \\
\text { through anonymous participation). }\end{array}$ \\
\hline $\begin{array}{l}\text { 8. Support the } \\
\text { user's } \\
\text { activities - } \\
\text { do not force }\end{array}$ & A & $\begin{array}{l}\text { OIE supports companies' products and service } \\
\text { development with a user-centric approach. Users } \\
\text { participate voluntarily. User's activity in OIE is } \\
\text { to join the community and participate in } \\
\text { activities on voluntary basis. OIE must take this } \\
\text { into account in all actions. }\end{array}$ \\
\hline $\begin{array}{l}\text { 9. Go for a } \\
\text { perfect } \\
\text { visual } \\
\text { design. }\end{array}$ & A & $\begin{array}{l}\text { In OIE this is related to digital tools mainly. Can } \\
\text { be seen also relating to on-site facilities. Visual } \\
\text { aspects can have influences on how users } \\
\text { experience the quality of the OIE. Visually } \\
\text { pleasurable (digital) tools can also increase } \\
\text { participation. }\end{array}$ \\
\hline $\begin{array}{l}\text { 10. Give a } \\
\text { surprise gift }\end{array}$ & A & $\begin{array}{l}\text { This is important especially in long-term use, } \\
\text { when motivation of users is challenging. In the } \\
\text { best case, the activity itself is the "surprise gift". } \\
\text { OIE must meet the needs of all stakeholders and } \\
\text { communicate the impact to users. }\end{array}$ \\
\hline
\end{tabular}

The analysis indicates that all ten UX heuristics are applicable in the OIE context and that the heuristics are important to take into account (Table 1). Especially, UX heuristic evaluation could be included into a set of methods (Guideline 5) and used for evaluating for new systems and services under investigation in OIE (e.g. when studying customers' products or services). The Fig. 1 shows that six UX heuristics are applicable with the guideline 6 (Digital tools). This indicates that digital tools of OIE should be developed by taking UX heuristics into account. However, all guidelines are not covered by UX heuristics, for instance, guidelines 3 and 4 cannot be evaluated by UX heuristics (Fig. 1). Therefore, creating an own set of guidelines is justified. Table I shows the analysis of applicability of UX heuristics in an OIE context.

The heuristics encompass the user point of view. However, in an open innovation environment, for instance, living labs, also other aspects need to be taken into account. These aspects are, for instance, resources and networks, costs and business model, digital tools and methods, operational responsibilities and facilities among others. Therefore, it is necessary to develop specific guidelines that take the other aspects into account. Open innovation environment is a complex combination of stakeholders (e.g. customers, professionals and users), different tools and facilities, and time- and cost-dependent actions, which all will have influence on user experiences (users of OIE, endusers of product and services, customer-user and operators of OIE). The Fig. 2 shows the difference of the focus between user experience heuristics and guidelines for facilitating user-centric product and service development in an open innovation environment.

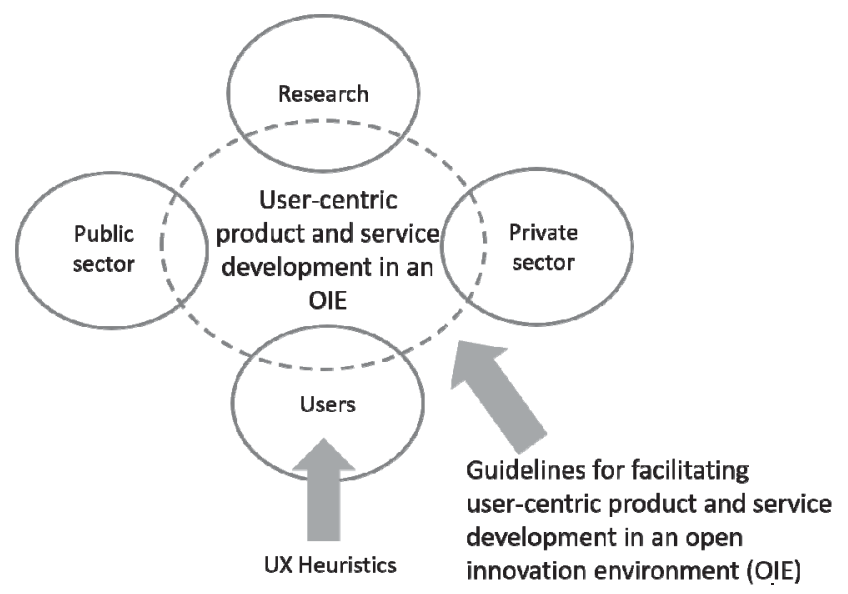

Fig. 2. Focus of UX Heuristics and OIE Guidelines

\section{THE REVISED SET OF GUIDELINES}

In order to facilitate a user-centric product and service development in an open innovation environment we propose guidelines which take into account the key success factors of OIE process and services. After the analysis, we revised guidelines and created the template which can be freely used for designing and evaluation open innovation environments (Fig. 3). The revised guidelines are described below.

\section{1) Functioning open innovation process}

Create a simple and smooth open innovation process where the different phases and related documentation (inputs and outputs) are clearly visible and understandable to different parties (e.g. customers, facilitators, users).

\section{2) Facilitation}

Create a set of efficient, adaptable and versatile facilitation techniques to be used in different open innovation activities (e.g. a set of techniques for certain phases of product development). Refine and apply new techniques regularly. 


\section{Guidelines for Facilitating User-Centric Product and Service Development in an Open Innovation Environment}

$\mathbf{0}=$ This guideline is not applicable with this OIE

$\mathbf{1}=$ This guideline is not reported, or information is not found

$\mathbf{2}=$ This guideline is not realized

$\mathbf{3}=$ This guideline is partially realized

$\mathbf{4}=$ This guideline is well realized
Evaluation date:

Name of OIE:

Status of OIE:

Evaluator's role:

existing OIE / new design / redesign designer / developer / researcher /

external consultant / other:

\begin{tabular}{|c|c|c|c|c|c|c|}
\hline \multirow[t]{2}{*}{ OIE Guidelines } & \multicolumn{5}{|c|}{ Points } & \multirow{2}{*}{$\begin{array}{l}\text { Notes and improvement ideas. Take into account } \\
\text { characteristics of OIE under investigation }\end{array}$} \\
\hline & 0 & 1 & 2 & 3 & 4 & \\
\hline \multicolumn{7}{|l|}{ 1. Functioning open innovation process } \\
\hline \multicolumn{7}{|l|}{ 2. Facilitation } \\
\hline \multicolumn{7}{|l|}{ 3. Resource-driven operations } \\
\hline \multicolumn{7}{|l|}{ 4. Funding model } \\
\hline \multicolumn{7}{|l|}{ 5. A versatile set of methods } \\
\hline \multicolumn{7}{|l|}{ 6. Digital tools } \\
\hline \multicolumn{7}{|l|}{ 7. Access to users } \\
\hline \multicolumn{7}{|l|}{$\begin{array}{l}\text { 8. Operating model for user } \\
\text { management, involvement and } \\
\text { motivation }\end{array}$} \\
\hline \multicolumn{7}{|l|}{ 9. A broad network of actors } \\
\hline \multicolumn{7}{|l|}{$\begin{array}{l}\text { 10. Operating model for network } \\
\text { collaboration }\end{array}$} \\
\hline \multicolumn{7}{|l|}{$\begin{array}{l}\text { 11. Communication and communication } \\
\text { of results }\end{array}$} \\
\hline \multicolumn{7}{|l|}{ 12. Follow-up } \\
\hline A number of each point & & & & & & \\
\hline
\end{tabular}

If achieved mainly points $\mathbf{1}$ and $\mathbf{2}$, there are major weaknesses or problems in the open innovation environment.

It is important to do strong actions to improve the OIE process.

If achieved mainly points 3 and 4, there are some minor deficiencies in the quality of the open innovation environment. It is important to improve the OIE process according to notes. 


\section{3) Resource-driven operations}

Ensure availability of sufficient resources and know-how from the open innovation environment network, for both permanent and temporary needs.

\section{4) Funding model}

Ensure public funding, project funding or other external funding (in addition to commercial activities) to enable the continuity and steadiness of open innovation environment operations (e.g. a living lab)

\section{5) A versatile set of methods}

Collect a set of methods that fits different needs e.g., in user involvement and evaluation. Develop methods further and apply them according to the users or customer needs in different contexts. Consider needs, timing and costs when selecting appropriate methods.

\section{6) Digital tools}

Digital involvement methods enable easy and smooth user involvement regardless of time and place. Develop and apply digital tools for varying needs of the open innovation environment. Pay attention to usability, visual design and security of the digital tools.

\section{7) Access to users}

Create a community of volunteer users and make sure you have a wide range of users involved. Develop a process for searching target-group specific users easily from the community. Keep in mind that each user experience and feedback about the product or service being tested are valuable.

8) Operating model for user management, involvement and motivation

Create a procedure for user community management, interaction, and communication. Improve user engagement through a range of activities, versatility, and also publicly accessible activities. Support and motivate user participation by providing various forms of interaction (online and onsite participation, verbal and non-verbal participation, device platforms: desktop, mobile, voice interaction). Reward users. Tell users that their opinion is important and provide guidance during the activity and feedback after each activity.

\section{9) A broad network of actors.}

Build a network of stakeholders, public organizations, research institutes and businesses that possess an interest, support, know-how and/or need for open innovation (e.g. living lab) activities.

\section{0) Operating model for network collaboration}

Define roles with the actors. When everyone has a clear role and goals, an open innovation environment is meaningful and effective.

\section{1) Communication and communication of results}

Promote the achievements and the results of the activities not only for users and the network of actors, but also for the wider public. Create need for open innovation (e.g. living lab) services through communication of impact.

\section{2) Follow-up}

Create a follow-up procedure and maintain connection to your customers to stay aware of the developments of the product/service and long-term outcome of the related innovation activities conducted in the open innovation environment.

\section{DISCUSSION}

In this paper, we propose a generic set of guidelines for facilitating user-centric product and service development in an open innovation environment. These guidelines have been developed on the basis of long-term qualitative studies with a broad range of open innovation cases conducted in an OIE. We see it important to share these experiences and guidelines with professionals and practitioners of the open innovation field.

However, due to the variation of different open innovation environments all guidelines may not be relevant for all OIEs. Therefore, we present these guidelines as general and flexible, to be used as a checklist as shown from the Fig. 3. The form can be used to support design and evaluation of open innovation environments.

In this paper we also analyzed the applicability of UX heuristics in an open innovation environment context. The analysis indicated that all UX heuristics are applicable and it is important to take them into account in the facilitation of an OIE. The heuristics focus on users' experiences, which is an important part of the open innovation environments and user involvement. However, the analysis revealed that design and evaluation of open innovation environments requires a broader approach. For instance, organizational point of views need to considered, for instance, resources, facilities, business and operational models, among others. Therefore, a need for guidelines for facilitating the whole versatile open innovation environment is justified. Well-working open innovation process and practices will have an immediate influence on all stakeholders.

\section{CONCLUSION}

This paper presented guidelines for facilitating user-centric product and service development in an open innovation environment. The aim of the guidelines is to help develop, evaluate and improve open innovation environments and practices e.g. in a living lab. These guidelines are based on the empirical experiences and lessons learned from various case studies conducted in an open innovation environment 20112018 [32]. These guidelines support the adoption of open innovation and living lab approach as a natural and continuous practice in different product and service development activities.

We believe that this set of generic guidelines is valuable to take into account in all kind of open innovation environments that aim to involve users in different stages of the product and service development. Processes and practices of open innovation environments should be smooth and effective to make an OIE successful. Therefore, it is important to deploy 
these guidelines and evaluate their applicability for example by conducting expert evaluations or analyzing different open innovation environment functions via them. Thus, we regard it as significant to share these guidelines with open innovation professionals and we encourage researchers and practitioners to utilize these guidelines in their open innovation environments.

\section{ACKNOWLEDGMENT}

The guidelines for facilitating open innovation environments presented in this paper have been developed based on the $\mathrm{PhD}$ of the first author and various case studies conducted in an open innovation environment 2011-2018 [32].

\section{REFERENCES}

[1] E. von Hippel. "Lead users". Management Science, 1986, 32(7), pp. 791-805

[2] C. Herstatt and E. von Hippel. "From experience: Developing new product concepts via the lead user method: A case study in a "lowtech" field". The Journal of Product Innovation Management, 1992, 9(3), pp. 213-221.

[3] H. Chesbrough. "Open innovation: The new imperative for creating and profiting from technology". Boston, Massachusetts: Harvard Business School Press. 2003.

[4] H.W. Chesbrough and M. Appleyard. "Open innovation and strategy". California Management Review, 2007, 50(1), pp. 57-76.

[5] H. Chesbrough, C., Lettl and T. Ritter. "Value creation and value capture in open innovation". Journal of Product Innovation Management, 2008, 35(6), pp. 930-938. doi:10.1111/jpim.12471

[6] J. West and M. Bogers. "Leveraging External Sources of Innovation: A Review of Research on Open Innovation". Journal of Product Innovation Management, 2014, 31(4), pp. 814- 831. doi:https://doi.org/10.1111/jpim.12125.

[7] C.R. Wilkinson and A. De Angeli. "Applying user centred and participatory design approaches to commercial product development". Design Studies, 2014, 35(6), pp. 614-631.

[8] M. Curley. "Twelve principles for open innovation 2.0: evolve governance structures, practices and metrics to accelerate innovation in an era of digital connectivity". Nature, 2016, 533(7603), pp. 314 316.

[9] B. Salmelin. "Living Labs and open Innovation in European Context". In: A. Mention and M. Torkkeli (Eds.), Open innovation: A multifaceted perspective. part I: 1-18. Imperial College Press, World Scientific. 2016.

[10] M. Torkkeli, O-P. Hilmola, P. Salmi, S. Viskari, H. Käki, M. Ahonen and S. Inkinen. Avoin innovaatio: Liiketoiminnan seitinohuet yhteistyörakenteet [Open Innovation: The thin cooperation structures of business]. Lappeenrannan teknillinen yliopisto, Kouvolan tutkimusyksikkö. Tutkimusraportti Nro. 190. Lappeenranta. 2007.

[11] A. Mention and M. Torkkeli. "Unfolding fifty shades of open innovation: Stimulating insights and foresights". In: A. Mention and M. Torkkeli (Eds.), Open innovation: A multifaceted perspective. part I: 2016, 1-18. Imperial College Press, World Scientific.

[12] W. Vanhaverbeke, F. Frattini, N. Roijakkers and M. Usman. (Eds.), Researching open innovation in SMEs. Cambridge University Press. 2018

[13] A. Følstad. "Living labs for innovation and development of information and communication technology: A literature review". The Electronic Journal for Virtual Organizations and Networks, 2008, 10: pp. 99-131.

[14] C. Dell'Era and P. Landoni. "Living lab: A methodology between User-Centred design and participatory design". Creativity and Innovation Management, 2014, 23(2), pp. 137-154.

[15] E. Almirall, M. Lee and J. Wareham. "Mapping living labs in the landscape of innovation methodologies". Technology Innovation Management Review, 2012, 2(9), pp. 12-18.

[16] T. Tang, Z. Wu, K. Karhu, M. Hämäläinen and Y. Ji. "Internationally distributed living labs and digital ecosystems for fostering local innovations in everyday life". Journal of Emerging Technologies in Web Intelligence, 2012, 4(1).
[17] A. Vermeeren, E. Law, V. Roto, M. Obrist, J. Hoonhout and K. Väänänen-Vainio-Mattila. "User Experience Evaluation Methods: Current State and Development Needs". Proc. NordiCHI 2010. ACM Press, (2010, pp. 521-530.

[18] B.J. Pine and J.H. Gilmore. "Welcome to the Experience Economy". Harvard Business Review. July-August 1998.

[19] P.W. Jordan. Designing Pleasurable Products, An introduction to the new human factors. New York, Taylor \& Francis, 2000.

[20] K. Väänänen-Vainio-Mattila and M. Wäljas. ”Developing an expert evaluation method for user eXperience of cross-platform web services". Proc. MindTrek 2009. ACM Press (2009), 162-169.

[21] ISO 9241-210:2010 (E). Ergonomics of human system interaction Part 210: Human-centred design for interactive systems. International Standardization Organization (ISO). Switzerland. 2010.

[22] M. Pakanen. Visual design examples in the evaluation of anticipated user experience at the early phases of research and development. Doctoral thesis. University of Oulu. 2015.

[23] W. Huang, M. Pakanen, L. Haukipuro, S. Väinämö and L. Arhippainen. "Motivate Online Users by Moderating and Providing Tasty Testing Experiences." The 22nd Conference of Open Innovations Association FRUCT, Jyväskylä, Finland, 15-18 May 2018.

[24] D. Norman (1988). The Design of Everyday Things. (Original title: The Psychology of Everyday Things). New York: Basic Books. ISBN 978-0-465-06710-7.

[25] J. Nielsen. "Ten Usability Heuristics". 2001. Web: https://www.nngroup.com/articles/ten-usability-heuristics/.

[26] B. Bergvall-Kåreborn and A. Ståhlbröst. "Living lab: An open and citizen-centric approach for innovation". International Journal of Innovation and Regional Development, 2009, 1(4), pp. 356-370. doi:10.1504/IJIRD.2009.022727

[27] L. Alben. "Quality of experience: Defining the criteria for effective interaction design". Interactions 1996, III3, May+June, pp. 11-15.

[28] H. Korhonen and E.M. Koivisto. "Playability heuristics for mobile games". Proc. MobileHCI '06, vol. 159. ACM, New York, NY, 2006, pp. 9-16.

[29] L. Colombo and M. Pasch. "10 Heuristics for an Optimal User Experience". Proc. CHI2012 Altchi. ACM Press, 2012.

[30] M. Csikszentmihalyi. "Flow - The Psychology of Optimal Experience. Steps Toward Enhancing the Quality of Life". New York, Harper Perennial. 1990

[31] L. Arhippainen. A Tutorial of Ten User Experience Heuristics. Tutorial in Academic MindTrek Conference, 1.10.2013. ACM Press, 2013. pp. 336-337.

[32] L. Haukipuro. User-centric product and service development in a multi-context living lab environment: case OULLabs and PATIO. Doctoral Thesis. Oulu: University of Oulu. 2019.

[33] K.M. Eisenhardt. "Building theories from case study research". The Academy of Management Review, 1989, 14(4), 532-550.

[34] R.K. Yin. (Eds.), Case study research — design and methods (2nd ed.). Newbury Park (CA): Sage Publications. 1989

[35] R.K. Yin. Case study research (3rd ed.). Thousand Oaks: Sage. 2005.

[36] R.E. Stake. The art of case study research. Thousand Oaks, CA: Sage. 1995.

[37] A. Dubois and L. Gadde. Systematic combining: An abductive approach to case research. Journal of Business Research, 2002, 55(7), pp. 553-560.

[38] A. Halinen and J. Törnroos. "Using case methods in the study of contemporary business networks". Journal of Business Research. 2005, 58(9): pp. 1285-1297.

[39] P. Baxter and S. Jack. "Qualitative case study methodology: Study design and implementation for novice researchers". The Qualitative Report, 2008, 13(4), pp. 544-559.

[40] J. Gustafsson and P.E. Nielsen. "Methodological challenges and lessons learned - deconstructing studies of social reality". Journal of African Media Studies, 2017, 9(2), pp. 247-260.

[41] G. Easton. Methodology and industrial networks. Norwell, MA: Kluwer Academic Publishing. 1995

[42] W.J. Johnston, M.P. Leach and A.H. Liu. "Theory Testing Using Case Studies in Business-to-Business Research". Industrial Marketing Management, 1999, 28(3), pp. 201-213.

[43] H. Arksey and P.T. Knight. Interviewing for social scientists. London: Sage. 1999.

[44] N.K. Denzin. The research act (3rd ed.). Chicago: Aldine. 1973. 
[45] N. Golafshani. "Understanding reliability and validity in qualitative research". The Qualitative Report, 2003, 8(4), 597.

[46] J. Aronson. "A Pragmatic View of Thematic Analysis". The Qualitative Report, 1994, 2, pp. 1-3.
[47] M.B Miles and A.M. Huberman (1994). Qualitative data analysis: An expanded sourcebook (2nd ed.). Thousand Oaks, CA: Sage Publications.

[48] M.B Miles, A.M. Huberman and S. Saldaña (2014). Qualitative Data Analysis. A Methods Sourcebook. (3 ${ }^{\text {rd }}$ ed.).CA: Sage Publications. 